\title{
Use of $\mathrm{Al}_{2} \mathrm{O}_{3}$ in an automated on-line pre-concentration system for determination of cadmium(II) by FAAS
}

\author{
Érica Silva Souza ${ }^{\mathrm{a}}$, Amarildo Otavio Martins ${ }^{\mathrm{b}}$, Humberto Vieira Fajardo ${ }^{\mathrm{a}}$, \\ Luiz Fernando Dias Probst ${ }^{\mathrm{a}}$, Eduardo Carasek ${ }^{\mathrm{a}, *}$ \\ ${ }^{a}$ Departamento de Química, Universidade Federal de Santa Catarina, 88040-900 Florianópolis, SC, Brazil

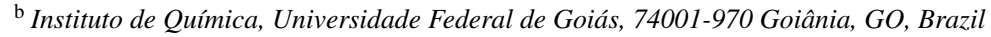 \\ Received 19 August 2006; received in revised form 20 April 2007; accepted 24 April 2007 \\ Available online 29 April 2007
}

\begin{abstract}
This paper presents the development of an on-line pre-concentration system to determine cadmium(II) in aqueous samples. The analyte was trapped in a mini-column filled with $\mathrm{Al}_{2} \mathrm{O}_{3}$ in the form of macro-spheres obtained by the mixture of $\mathrm{Al}\left(\mathrm{NO}_{3}\right)_{3} \cdot 9 \mathrm{H}_{2} \mathrm{O}_{\text {aq }}$ and chitosan dissolved in acetic acid. The mixture was dropped into an $\mathrm{NH}_{4} \mathrm{OH}$ aqueous solution under rigorous agitation using a peristaltic pump, the macro-spheres were separated from alkaline solution and dried, and finally were submitted to thermal treatment. The pre-concentration system was linear between 1.0 and $100 \mu \mathrm{g} \mathrm{L}^{-1}$, with a linearity of 0.999 , sensitivity of $3.58 \times 10^{-3} \mathrm{~L}^{-1}$ and enrichment factor of 21.9. The limits of detection and quantification were $0.08 \mu \mathrm{g} \mathrm{L}^{-1}$ and $0.28 \mu \mathrm{g} \mathrm{L}^{-1}$, respectively. The repeatability was between 2.6 and $5.9 \%$. Recovery tests were carried out with a real aqueous sample.
\end{abstract}

(C) 2007 Elsevier B.V. All rights reserved.

Keywords: Alumina; Pre-concentration; Cadmium(II); Flame atomic absorption spectrometry

\section{Introduction}

Environmental pollution of natural waters by toxic inorganic cadmium arises mainly from industrial effluents and wastewater disposal from different sources, such as nickel-cadmium batteries, pigments, chemical stabilizers, alloys and fertilizers. Its presence in abnormally high levels can cause a series of adverse reactions [1]. According to the World Health Organization, the maximum permissible level of cadmium in drinking water is $3.0 \mu \mathrm{g} \mathrm{L}^{-1}$ [2]. Hence, the analytical control of cadmium in drinking water is becoming an increasingly important issue, and sensitive analytical techniques to obtain adequate detection limits are in demand.

Several techniques are used for $\mathrm{Cd}$ determination including flame atomic absorption spectrometry (FAAS), electrothermical atomic absorption spectrometry, inductively coupled plasmamass spectrometry, inductively coupled plasma optical emission spectrometry and instrumental neutron activation analysis [3].

\footnotetext{
* Corresponding author. Tel.: +55 48 37216852; fax: +55 4837216852

E-mail addresses: carasek@qmc.ufsc.br, eduardo.carasek@pesquisador.cnpq.br (E. Carasek).
}

FAAS is one of the most commonly applied techniques for the determination of several metallic and semi-metallic elements, in a variety of sample types, due to its low equipment cost and high analytical throughput. However, this technique has some limitations, mainly those related to sensitivity, which can be attributed to the limited sampling efficiency and short residence time of the analytes in the flame [4]. These problems can be overcome by using an on-line pre-concentration system [5-7], developed to improve the conventional procedures and to decrease the risks of contamination. Of the several pre-concentration methods, solidphase extraction (SPE) is one of the most effective methods due to its simplicity, ease of automation, recovery of the solid phase and high analytical throughput $[1,8]$. SPE is an attractive technique for analytical chemistry due to the great availability of sorbent materials. In general, the sorbent has fast metal ionexchange kinetics, resistance in different solvents and thermal and chemical stability $[9,10]$.

The procedure of cadmium complexation with 1-nitroso-2naphthol, followed by retention on Amberlite XAD-4 resin, has been applied in the determination of cadmium in chemical grade potassium salts, with a detection limit of $16 \mathrm{ng} \mathrm{L}^{-1}$ [11]. The Chelex-100 resin has been used to determine cadmium in black 
tea, and some certified reference materials, having a detection limit of $17 \mathrm{ng} \mathrm{L}^{-1}$ [12]. Also, cadmium has been enriched after SPE as dibenzyldithiocarbamate chelates on Dowex Optipore V493 and determined by FAAS. Under the optimized conditions, this procedure gave a detection limit for cadmium of $0.43 \mu \mathrm{g} \mathrm{L}^{-1}$ [13]. Amberlite XAD-2 functionalized with dithizone was also applied for the determination of cadmium in seawater resulting in a detection limit of $6.7 \mathrm{ng} \mathrm{L}^{-1}$ [14]. The determination of cadmium from waste, tap and mineral waters has been studied using a SPE system with alumina modified with sodium dodecyl sulfate and 1-(2-pyridylazo)-2-naphthol. This system reached a detection limit for cadmium of $24.3 \mathrm{ng} \mathrm{L}^{-1}$ [15]. Furthermore, it has been demonstrated that alumina has a great potential for solid-phase extraction because of its high versatility [16-19]. It can function as both a cation and an anion exchanger, depending on the solution $\mathrm{pH}$; under basic conditions it shows a high affinity for a wide range of cationic species while, under acidic conditions it exhibits a high affinity for anionic species [20].

Analytical methods can be developed in two different ways: (i) conventional optimization, using the univariate or "one variable at a time" mode and (ii) the multivariate technique. The use of the univariate mode leads to easier interpretation, but requires a great amount of reagents and time, and interactions between variables are not considered. The multivariate technique, which is faster, more economical and effective, allows the variables to be optimized simultaneously [21]. In this technique, the factorial design allows the identification of the significant variables of an experiment, and indicates conditions for better results. One of the most popular multivariate designs is the two-level full (or fractional) factorial, in which every factor is experimentally studied at only two levels. Due to their simplicity and relatively low cost, full factorial designs are very useful for preliminary studies or the initial steps of optimization, while fractional designs are almost mandatory when the problem involves a large number of factors [2,21]. Doehlert designs, proposed in 1970, can be used for an optimization refinement of the analytical system. They have the advantage of requiring fewer experimental runs than a full composite design, to fit a given higher-order model [22]. They have wide applications in several areas of science and in an experiment they allow the identification of the significant variables indicating conditions for a better analytical response. Another advantage is the central point-projection (CP) that results in a higher efficiency value. The Doehlert matrix results in a surface response (which can be a maximum, minimum or saddle point) and its equation indicates the critical point [22-25].

The purpose of this study is to verify the viability of the application of mesoporous alumina, and alumina with a large surface area, for the development of an analytical methodology for the determination of cadmium in aqueous samples.

\section{Experimental}

\subsection{Instrumentation}

A Varian Model SpectrAA 50 (Australia) flame atomic absorption spectrometer was used for the analysis. The cadmium cathode lamp (Hitachi HLA-4S) was used under conditions suggested by the manufacturer (current, $4 \mathrm{~mA}$ ). The wavelength $(228.8 \mathrm{~nm})$, slit bandwidth $(1 \mathrm{~nm})$ and burner height $(7.5 \mathrm{~mm})$ used were also the recommended values. The flame composition was acetylene (flow rate, $\left.2 \mathrm{~L} \mathrm{~min}^{-1}\right)$ and air $\left(10 \mathrm{~L} \mathrm{~min}^{-1}\right)$. Aspiration flow rate was $5.5 \mathrm{~mL} \mathrm{~min}^{-1}$. The analytical signals were measured as peak height. A 320 Mettler Toledo pH meter was used to adjust the $\mathrm{pH}$ of the solutions. An Ismatec-IPC peristaltic pump with eight channels provided with Tygon ${ }^{\circledR}$ and polyethylene tubes with $0.8 \mathrm{~mm}$ internal diameter (i.d.) were used to pump the solutions through the mini-column. A manifold with four three-way solenoid valves was used to select pre-concentration and elution steps. The connections of the pre-concentration flow system were made of Y-shaped Teflon. Solenoid valves were controlled by a microcomputer running software written in Quick Basic 4.5.

\subsection{Reagents and solutions}

Ultrapure water from a Milli- $\mathrm{Q}^{\circledR}$ (Bedford, MA, USA) water purification system (Millipore ${ }^{\circledR}$ ) was used to prepare all solutions. All chemicals were of analytical grade and were used without previous purification. The laboratory glassware was kept overnight in a 2\% (v/v) Extran ${ }^{\circledR}$ (Merck) solution and then again overnight in a $10 \%$ (v/v) nitric acid solution. Before use, the glassware was washed with deionized water and dried in a dust-free environment.

Working standard solutions of Cd(II) $\left(1-100 \mu \mathrm{g} \mathrm{L}^{-1}\right)$ were prepared by dilution of $2000 \mathrm{mg} \mathrm{L}^{-1}$ cadmium(II) stock solution (Carlo Erba, Milan, Italy). Nitric acid solutions (Merck, Germany) used as eluent in the flow system were prepared by appropriate dilution with water from the concentrated acid.

Acetic acid-acetate buffer ( $\mathrm{pH} 4.4)$ was prepared by mixing $2 \mathrm{~mol} \mathrm{~L}^{-1}$ acetic acid solution (Carlo Erba) and $2 \mathrm{~mol} \mathrm{~L}^{-1}$ sodium acetate solution (Vetec, Brazil) in a ratio of 1:0.75. Sorensen buffer solution ( $\mathrm{pH}$ 6.7) was prepared by mixing $0.084 \mathrm{~mol} \mathrm{~L}^{-1} \mathrm{Na}_{2} \mathrm{HPO}_{4}$ and $0.067 \mathrm{~mol} \mathrm{~L}^{-1} \mathrm{KH}_{2} \mathrm{PO}_{4}$ (Vetec) in a ratio of 1:0.02. Tris(hydroxymethyl)aminemethane buffer was prepared by dissolving $0.6 \mathrm{~g}$ of $\left(\mathrm{HOCH}_{2}\right)_{3} \mathrm{CNH}_{2}$ (Aldrich, Milwaukee, USA) in water adjusting the $\mathrm{pH}$ to 8.1 .

\subsection{Preparation of alumina}

The $\mathrm{Al}_{2} \mathrm{O}_{3}$ was prepared dissolving $4.60 \mathrm{~g}$ of the $\mathrm{Al}\left(\mathrm{NO}_{3}\right)_{3} \cdot 9 \mathrm{H}_{2} \mathrm{O}$ (Riedel-de-Häen) in $200 \mathrm{~mL}$ of distillated water. The biopolymer chitosan solution was prepared dissolving $1.50 \mathrm{~g}$ of the biopolymer (Merck) in $50 \mathrm{~mL}$ of a $5 \%(\mathrm{v} / \mathrm{v})$ acetic acid solution. The $\mathrm{Al}_{2} \mathrm{O}_{3}$ macro-spheres were obtained by mixing both solutions in a ratio of $2: 1.5$ and, using a peristaltic pump, were dropped into a $40 \%(\mathrm{v} / \mathrm{v}) \mathrm{NH}_{4} \mathrm{OH}$ aqueous solution under rigorous agitation. The macro-spheres were separated with a funnel (büchnner) from alkaline solution and dried at room temperature for $72 \mathrm{~h}$. Finally, the macro-spheres were submitted to thermal treatment in air at temperatures of 350,550 and $700{ }^{\circ} \mathrm{C}$ for $1 \mathrm{~h}$.

A mini-column with length and i.d. of 50 and $3 \mathrm{~mm}$, respectively, was filled with $50 \mathrm{mg}$ of $\mathrm{Al}_{2} \mathrm{O}_{3}$ submitted to thermal 


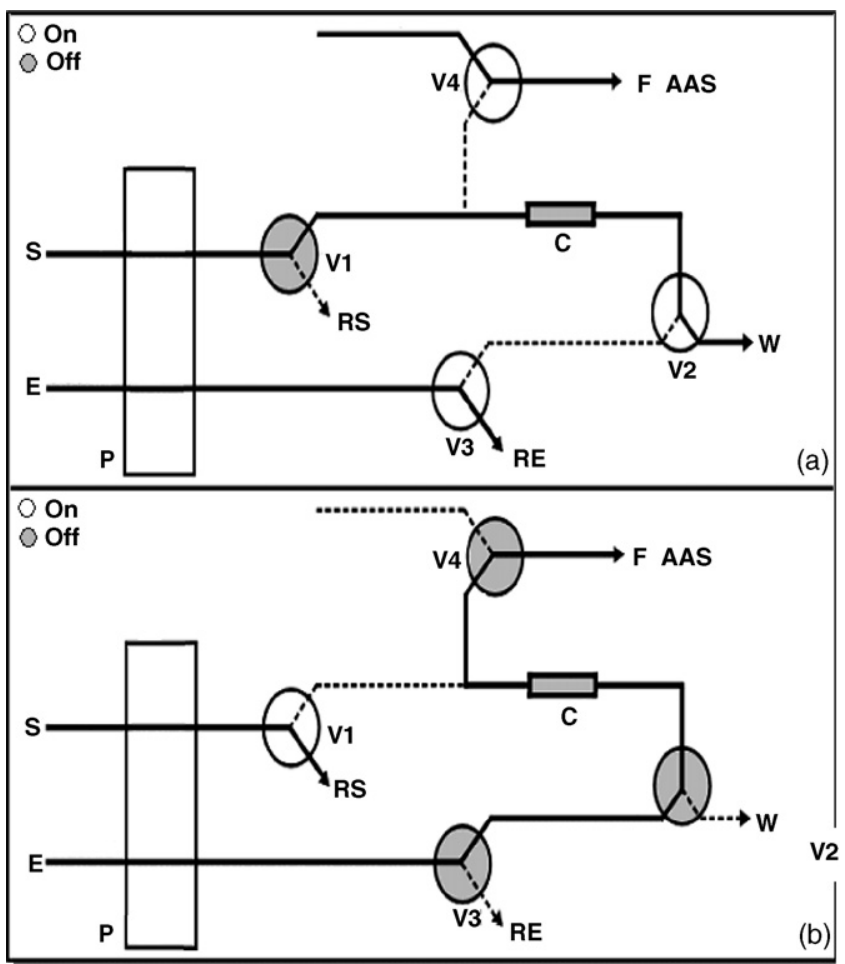

Fig. 1. On-line pre-concentration system: (a) adsorption step and (b) desorption step. (S) Sample, (E) eluent, (P) peristaltic pump, (C) mini-column, (V1, V2, V3 and V4) solenoid valves, (FAAS) flame absorption atomic spectroscopy, (RS) return of the sample, (RE) return of the eluent and (W) waste.

treatment at $550^{\circ} \mathrm{C}$, which was used as the adsorbent material. The ends of this mini-column were sealed with small glass wool beds to prevent material losses. The mini-column was coupled to a flame atomic absorption spectrometer.

\subsection{On-line pre-concentration system}

The diagram of the flow system is shown schematically in Fig. 1. The flow system comprised a peristaltic pump fitted with
Tygon tubing, four three-way solenoid valves and a mini-column filled with $\mathrm{Al}_{2} \mathrm{O}_{3}$. It was coupled to a flame atomic absorption spectrometer. In the sample-loading step, the valve V1 was initially open and the others were off, so that $15 \mathrm{~mL}$ of sample or standard solution (S) was pumped at $8.5 \mathrm{~mL} \mathrm{~min}^{-1}$ through the mini-column where ion exchange takes place and the effluent flows towards the waste (W). After that, the valve V1 was turned off and V2, V3 and V4 were opened and the eluent percolated through the mini-column at a flow rate of $5.5 \mathrm{~mL} \mathrm{~min}^{-1}$ displacing the $\mathrm{Cd}$ (II) ions from the adsorbent. The eluate was taken directly to the nebulizer-burner system of the flame atomic absorption spectrometer.

\section{Results and discussion}

\section{1. $\mathrm{Al}_{2} \mathrm{O}_{3}$ characterization}

After calcination at $350{ }^{\circ} \mathrm{C}$, the $\mathrm{Al}_{2} \mathrm{O}_{3}$ sample was black in color, indicating the presence of residual carbon. On the other hand, the samples heat-treated at 550 and $700{ }^{\circ} \mathrm{C}$ were white in color, which indicates the elimination of carbon. The $\mathrm{N}_{2}$ adsorption/desorption isotherms of the $\mathrm{Al}_{2} \mathrm{O}_{3}$ samples show type-IV (IUPAC) curves, indicating a mesoporous material. In contrast, the $\mathrm{Al}_{2} \mathrm{O}_{3}$ sample heat-treated at $350^{\circ} \mathrm{C}$ shows a microporous isotherm (Fig. 2a). The pore size distributions of the samples (Fig. 2b) confirm the presence of micropores for the sample heat-treated at $350^{\circ} \mathrm{C}$, but with an increase in the calcination temperature mesopore formation is significantly favored. This behavior is attributed to the carbon elimination at the higher treatment temperatures. With heat-treatment at $350{ }^{\circ} \mathrm{C}$, the amount of residual material is still high. However, as summarized in Table 1, the higher surface area and the lower total pore volume of the sample heat-treated at $350{ }^{\circ} \mathrm{C}$ may be due to the small pore size. The residual carbon elimination by heating at 550 and $700^{\circ} \mathrm{C}$ resulted in a surface area decrease and thus, the residual carbon is thought to contribute significantly to a higher surface area. On the other hand, the carbon elimina-
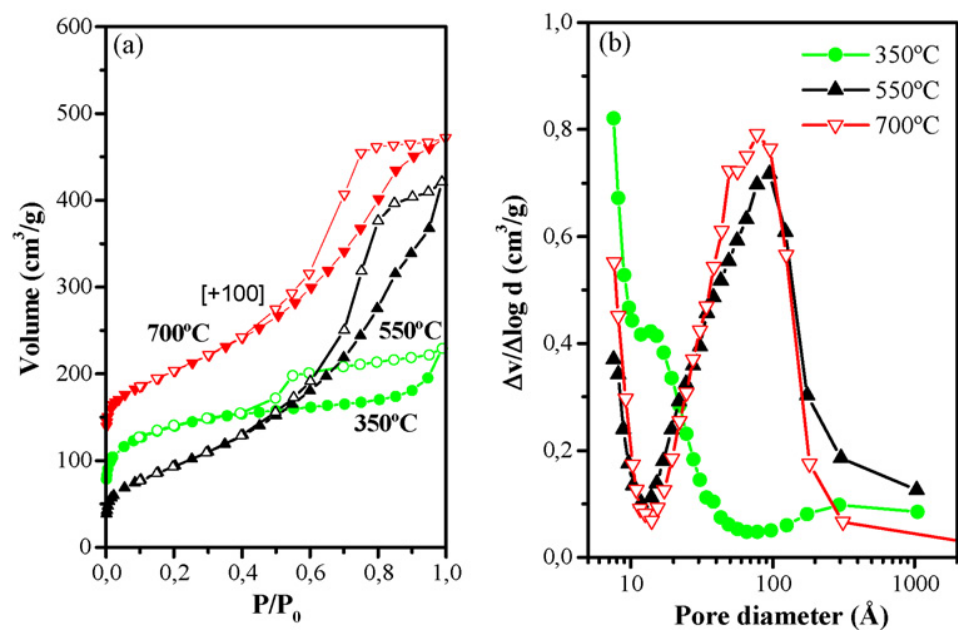

Fig. 2. (a) Nitrogen adsorption/desorption isotherms of samples heat-treated at different temperatures: (a) closed symbols for adsorption and open symbols for desorption branch and (b) pore size distribution of the samples. 

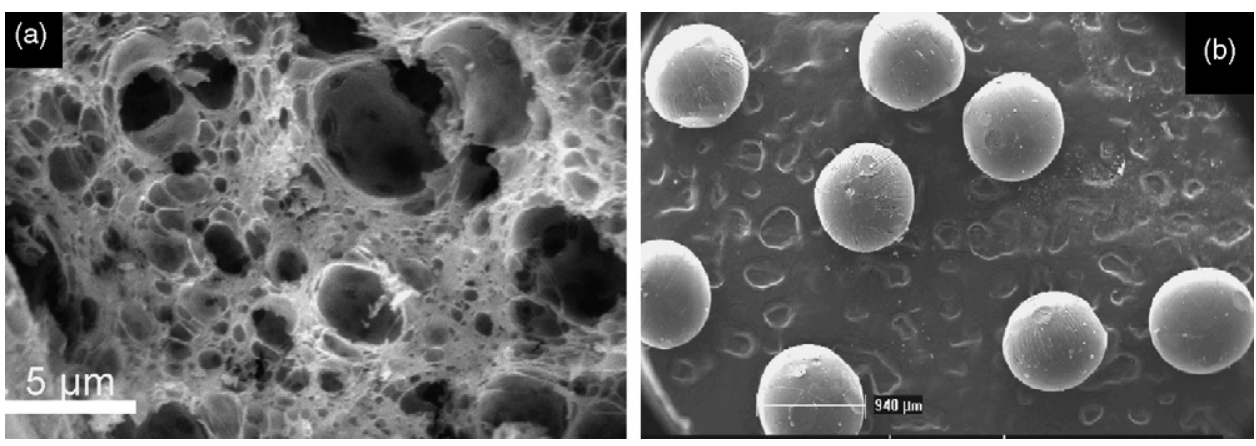

Fig. 3. SEM images for the macro-spheres heat-treated at $550^{\circ} \mathrm{C}$ : (a) porous macro-spheres $\mathrm{Al}_{2} \mathrm{O}_{3}$ and (b) macro-spheres mean size $940 \mu \mathrm{m}$.

Table 1

Surface properties measured by $\mathrm{N}_{2}$ physisorption

\begin{tabular}{llll}
\hline Samples & $T_{\mathrm{c}}\left({ }^{\circ} \mathrm{C}\right)$ & $S\left(\mathrm{~m}^{2} \mathrm{~g}^{-1}\right)$ & $V_{\mathrm{p}}\left(\mathrm{cm}^{3} \mathrm{~g}^{-1}\right)$ \\
\hline $\mathrm{Al}_{2} \mathrm{O}_{3}$ & 350 & 464 & 0.354 \\
$\mathrm{Al}_{2} \mathrm{O}_{3}$ & 550 & 343 & 0.651 \\
$\mathrm{Al}_{2} \mathrm{O}_{3}$ & 700 & 313 & 0.581 \\
\hline
\end{tabular}

$\left(T_{\mathrm{c}}\right)$ calcination temperature, $(S)$ specific surface area and $\left(V_{\mathrm{p}}\right)$ total pore volume.

tion promoted a great increase in the total pore volume, which suggests that the residual carbon present within the pore of the crystalline matrix is an amorphous carbon with high surface area. Burning out the residual carbon generated pores, which leads to mesopore formation and an increase in the total pore volume.

The scanning electron microscopy (SEM) images shown in Fig. 3a show the $\mathrm{Al}_{2} \mathrm{O}_{3}$ spheres heat-treated at $550^{\circ} \mathrm{C}$. In spite of the low number of spheres presented in this figure, the mean size was around $940 \mu \mathrm{m}$. The SEM image shown in Fig. $3 \mathrm{~b}$ shows a pore diameter size quite different to that determined by the $\mathrm{N}_{2}$ adsorption isotherm, but it does show the morphology, which is due to the utilization of organic compounds in the catalyst preparation. During the pyrolysis step, the elimination of volatile materials occurs, which produces cavities as a result of their removal. At the same time, a solid rearrangement may take place, forming the crystalline matrix. Fig. 4 shows the diffraction peaks of the samples. The results indicate the presence of the $\gamma-\mathrm{Al}_{2} \mathrm{O}_{3}$ phase in the temperature range studied.

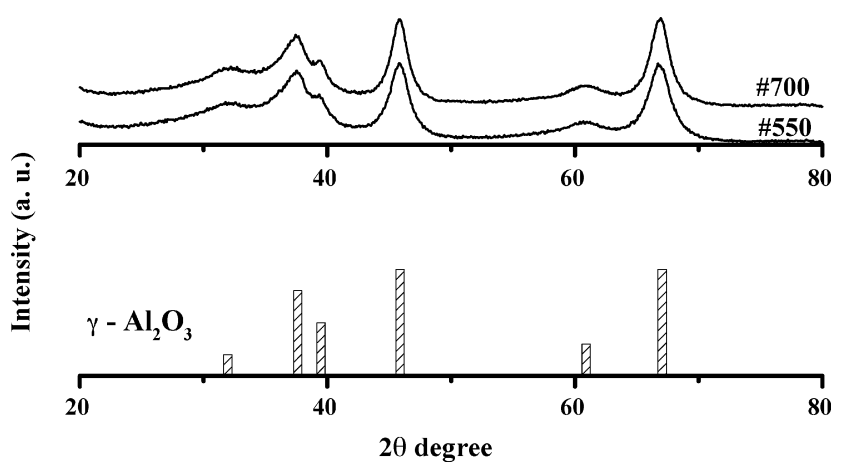

Fig. 4. X-ray diffraction patterns for the samples heat-treated at 550 and $700^{\circ} \mathrm{C}$.

\subsection{Factorial design}

The factors chosen (chemical and flow variables), considering the on-line pre-concentration system, were eluent flow rate, sample flow rate, eluent concentration and sample $\mathrm{pH}$. A two-level full factorial design 24 with a central point (C), and 17 runs in total was carried out in duplicate to determine the influence of the selected factors and their interactions in the pre-concentration system. All experiments were carried out in duplicate and $15.0 \mathrm{~mL}$ of cadmium(II) working solution in a concentration of $50 \mu \mathrm{g} \mathrm{L}^{-1}$ was used. Table 2 shows the values of each factor selected in this study. Analysis of variance (ANOVA) and $P$-values were used to check the significance of the effects on the pre-concentration system. The main effects and their interactions can be observed in the Pareto chart shown in Fig. 5. The absorbance and the sensibility efficiency were used as the analytical signal. According to these charts, the factors of sample $\mathrm{pH}$ and sample flow rate, and their interactions, are highly significant. The positive values obtained in this study indicate that by optimizing these factors, the analytical signal will increase.

\subsection{Response surface}

The results obtained by factorial design demonstrated the necessity for a final optimization of the sample $\mathrm{pH}$ and sample flow rate variables. The factors eluent concentration and eluent flow rate were not significant and were fixed at $0.25 \mathrm{~mol} \mathrm{~L}^{-1}$ and $5.5 \mathrm{~mL} \mathrm{~min}^{-1}$, respectively. The significant variables (sample $\mathrm{pH}$ and sample flow rate) were optimized using a Doehlert matrix. In this study, seven experiments were carried out as shown in Table 3. All experiments were carried out in duplicate. The sensibility efficiency obtained in this experiment was used as an input for the Doehlert matrix to obtain the surface responses shown in Fig. 6. Eq. (1) represents

Table 2

Variables and levels used in the factorial planning for $\mathrm{Cd}(\mathrm{II})$ with $\mathrm{Al}_{2} \mathrm{O}_{3}$

\begin{tabular}{llll}
\hline Variables & $\begin{array}{l}\text { Low level } \\
(-)\end{array}$ & $\begin{array}{l}\text { High level } \\
(+)\end{array}$ & $\begin{array}{l}\text { Central point } \\
(0)\end{array}$ \\
\hline Eluent flow rate $\left(\mathrm{mL} \mathrm{min}^{-1}\right)$ & 2.00 & 5.50 & 3.75 \\
Sample flow rate $\left(\mathrm{mL} \mathrm{min}^{-1}\right)$ & 2.00 & 5.50 & 3.75 \\
Sample $\mathrm{pH}$ & 4.07 & 8.10 & 6.05 \\
Eluent $\left[\mathrm{HNO}_{3}\right]\left(\mathrm{mol} \mathrm{L}^{-1}\right)$ & 0.25 & 2.50 & 1.30 \\
\hline
\end{tabular}



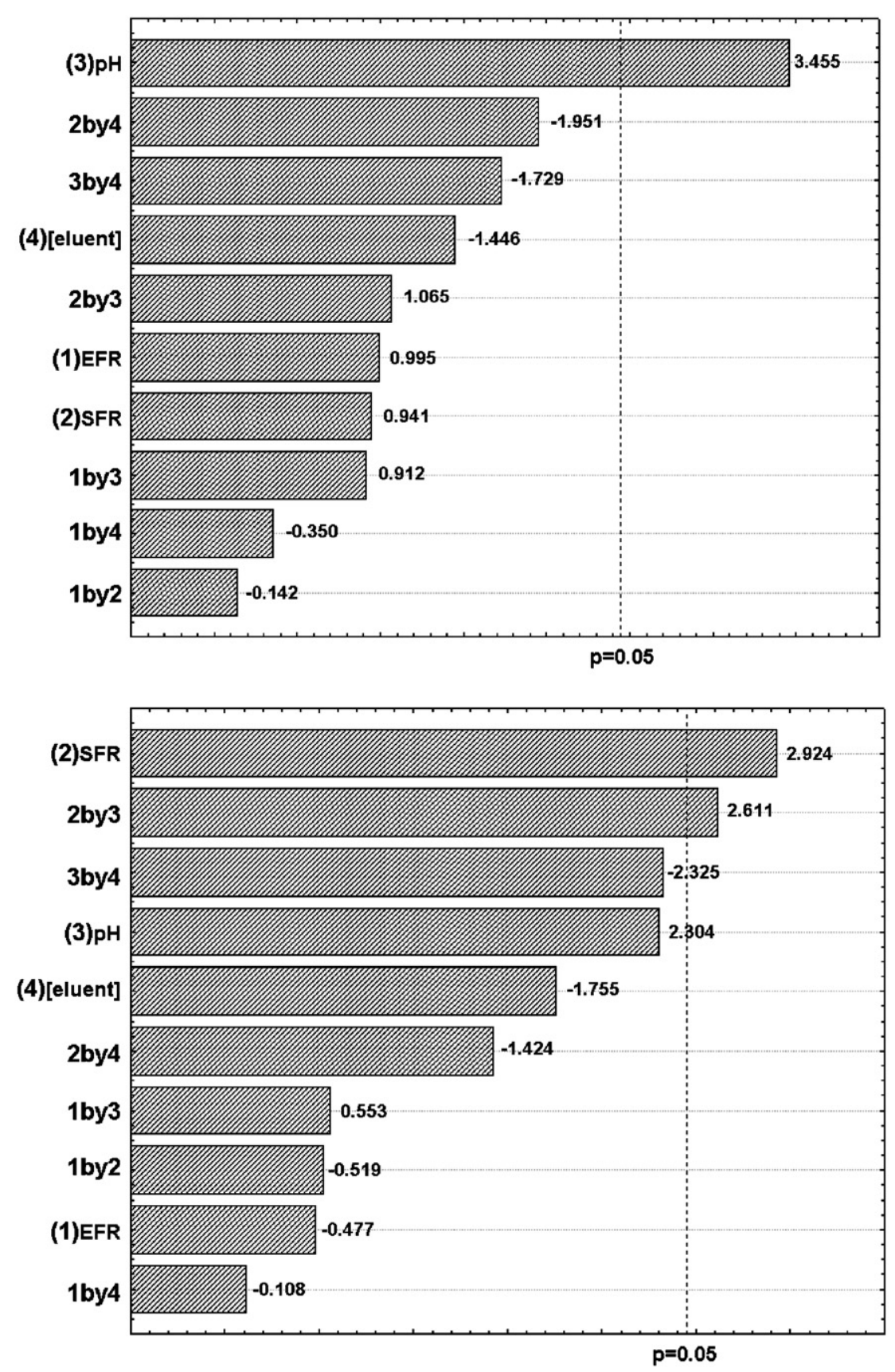

Fig. 5. Pareto chart obtained for full factorial design: (A) absorbance signal and (B) efficiency of signal. SFR, sample flow rate; EFR, eluent flow rate; [eluent], eluent concentration.

Table 3

Doehlert matrix used to optimize the sample $\mathrm{pH}$ and the sample flow rate

\begin{tabular}{lcll}
\hline Experiment number & Sample $\mathrm{pH}$ & Sample flow rate $\left(\mathrm{mL} \mathrm{min}^{-1}\right)$ & $\mathrm{ES}$ \\
\hline 1 & 7 & 5.5 & 0.1462 \\
2 & 7 & 8.5 & 0.2170 \\
3 & 9 & 5.5 & 0.0052 \\
4 & 9 & 8.5 & 0.0064 \\
5 & 9 & 7.0 & 0.0414 \\
6 & 8 & 7.0 & 0.0665 \\
7 & 10 & 7.0 & 0.0409 \\
\hline
\end{tabular}

the response surface when sensibility efficiency was used as the analytical response, and $x$ and $y$ represent, respectively, the sample $\mathrm{pH}$ and sample flow rate.

$$
\begin{aligned}
Z= & -0.107+0.153 x-0.104 y-0.006 x^{2} \\
& -0.012 x y+0.015 y^{2}
\end{aligned}
$$

Lagrange's criteria were used to determine the maximum point (Eqs. (2) and (3)):

$$
\frac{\partial z}{\partial x}=0.153-0.012 x-0.012 y
$$


$\frac{\partial z}{\partial y}=-0.104-0.012 x+0.030 y$

The values corresponding to the maximum are sample $\mathrm{pH} 6.6$ and sample flow rate higher than $8.5 \mathrm{~mL} \mathrm{~min}^{-1}$. However, in this study, a sample flow rate of 8.5 was used to avoid leaks in the flow system observed at higher flow rates.

\subsection{Effect of foreign ions}

The effect of potential interfering species in the determination of $100 \mu \mathrm{g} \mathrm{L}^{-1}$ of cadmium(II) was studied. In this study, different foreign ions ranging from 0.5 to $100 \mathrm{mg} \mathrm{L}^{-1}$ were introduced into the working solution. The species that changed the $\mathrm{Cd}$ (II) signal by more than $10 \%$ in the working solution were considered as interfering species. Results showed that nitrate, carbonate, sulfate, phosphate, chlorite, sodium(I) and silver(I) did not interfere in the FAAS after the pre-concentration process developed in this study. Other ions showed interference in the FAAS after pre-concentration by this procedure. However, this interference occurred only for concentrations higher than the following: potassium(I) $\left(80 \mathrm{mg} \mathrm{L}^{-1}\right)$, calcium(II) $\left(80 \mathrm{mg} \mathrm{L}^{-1}\right)$, barium(III) $\left(80 \mathrm{mg} \mathrm{L}^{-1}\right)$, copper(II) $\left(0.50 \mathrm{mg} \mathrm{L}^{-1}\right)$, zinc(II) $\left(1 \mathrm{mg} \mathrm{L}^{-1}\right)$, lead(II) $\left(3 \mathrm{mg} \mathrm{L}^{-1}\right)$ and iron(III) $\left(1 \mathrm{mg} \mathrm{L}^{-1}\right)$.

\subsection{Analytical features}

The calibration graph obtained using optimized conditions is given as $A=0.00386+0.00358 \times C$ in the linear range of $1-100 \mu \mathrm{g} \mathrm{L}^{-1}$, where $C$ is cadmium(II) concentration in solution $\left(\mu \mathrm{g} \mathrm{L}^{-1}\right)$. The correlation coefficient obtained from this graph was 0.9996. The limit of detection (LOD) was calculated as $3 \sigma / S$, where $S$ is the slope of the calibration curve and $\sigma$ is the standard deviation of 11 consecutive measurements of the blank solution. The LOD value was $0.08 \mu \mathrm{g} \mathrm{L}^{-1}$ in $15 \mathrm{~mL}$ of the blank solution. The precision of the procedure, calculated

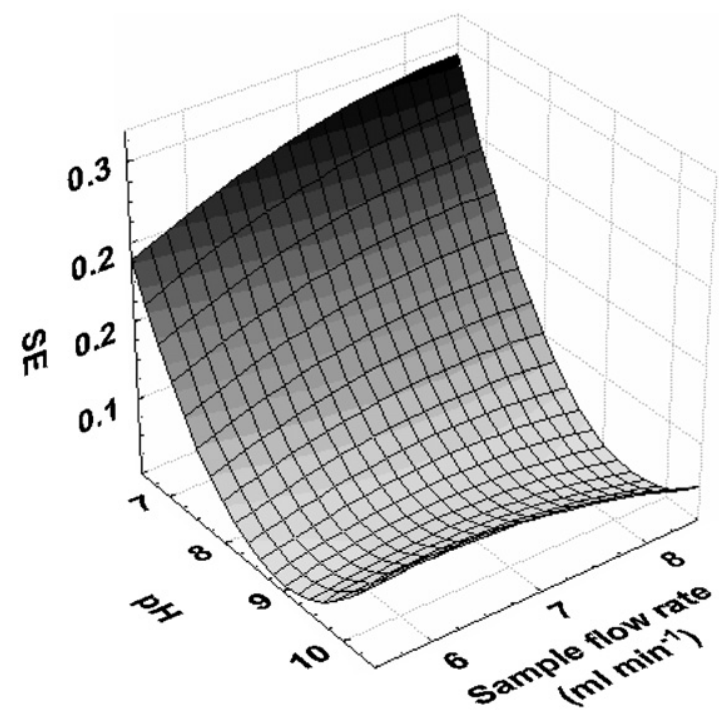

Fig. 6. Response surface obtained using Doehlert matrix to optimize sample pH and sample flow rate. as relative standard deviation of seven consecutive measurements of 1 and $25 \mu \mathrm{g} \mathrm{L}^{-1}$ cadmium(II) solution were 2.6 and $5.9 \%$, respectively. The enrichment factor, calculated as the ratio of the slopes of the calibration graphs with and without pre-concentration was 21.9. The alumina mini-column was saturated with $888.55 \pm 124.01 \mu \mathrm{g} \mathrm{g}^{-1}$ of cadmium(II) per gram of sorbent.

The proposed method was applied to the analysis of tap water samples collected from 10 different points in the city of Florianópolis, Brazil. The concentrations of the analyte in the water samples were below the detection limit of the method, and as there was no spiking of the samples the metal ion could not be detected. In order to evaluate the accuracy of the preconcentration procedure, recovery experiments were carried out with spiked water samples (two levels of enhancement, 5 and $50 \mu \mathrm{g} \mathrm{L}^{-1}$ ). The efficiency of the on-line pre-concentration system was very good for all samples analyzed, resulting in recoveries were between 101 and $110 \%$. The accuracy of the proposed method was also investigated by analyzing a drinking water reference material A1071 (Alpha Resource, Stevensville, MI, USA). The values for cadmium ion determined in the standard reference material were in agreement with the certified data.

\section{Conclusions}

The use of full factorial and Doehlert designs allows the optimization of the proposed system, while taking the interactions between the variables into consideration. This procedure was demonstrated to be more efficient than the univariate method and required a low number of experiments. The efficiency of the on-line pre-concentration system was very good for all tap water samples analyzed, with recoveries close to $100 \%$, indicating that the matrix effect was not significant. The interference study indicates that other types of samples could be analyzed using the proposed procedure. The sorbent developed in this study resulted in an efficient analytical performance in an online pre-concentration system. The alumina was shown to be chemically stable in all the analyses carried out in this study. The method employed had good accuracy for the recovery test carried out on real samples, low limits of detection, good precision and relatively high adsorption kinetics, which resulted in greater analytical throughputs.

\section{Acknowledgements}

The authors thank Coordenação de Aperfeiçoamento de Pessoal de Nível Superior (CAPES) and Fundação de Apoio a Pesquisa Cientifica e Tecnologica do Estado de Santa Catarina (FAPESC) for financial support.

\section{References}

[1] Y. Liu, X. Chand, S. Wang, Y. Guo, B. Din, S. Meng, Solid-phase extraction and preconcentration of cadmium(II) in aqueous solution with $\mathrm{Cd}(\mathrm{II})$ imprinted resin (poly-Cd(II)-DAAB-VP) packed columns, Anal. Chim. Acta 519 (2004) 173-179. 
[2] S. Cerutti, S.L.C. Ferreira, J.A. Gásquez, R.A. Olsina, L.D. Martinez, Optimization of the preconcentration system of cadmium with 1-(2thiazolylazo)- $p$-cresol using a knotted reactor and flame atomic absorption spectrometric detection, J. Hazard. Mater. 112 (2004) 279-283.

[3] E.J. Santos, A.B. Herrmann, A.S. Ribeiro, A.J. Curtius, Determination of $\mathrm{Cd}$ in biological samples by flame AAS following on-line preconcentration by complexation with $O$-diethyldithiophosphate and solid-phase extraction with Amberlite XAD-4, Talanta 65 (2005) 593-597.

[4] C.R.T. Tarley, S.L.C. Ferreira, M.A.Z. Arruda, Use of modified rice husks as a natural solid adsorbent of trace metals: characterisation and development of an on-line preconcentration system for cadmium and lead determination by FAAS, Microchem. J. 77 (2004) 163-175.

[5] A.O. Martins, E.L. Silva, M.C.M. Laranjeira, V.T. Fávere, Application of chitosan functionalized with 8-hydroxyquinoline: determination of lead by flow injection flame atomic absorption spectrometry, Microchim. Acta 150 (2005) 27-33.

[6] A.O. Martins, E.L. Silva, E. Carasek, N.S. Gonçalves, M.C.M. Laranjeira, V.T. Fávere, Chelating resin from functionalization of chitosan with complexing agent 8-hydroxyquinoline: application for metal ions on-line preconcentration system, Anal. Chim. Acta 521 (2004) 157-162.

[7] A.O. Martins, E.L. Silva, E. Carasek, M.C.M. Laranjeira, V.T. Fávere, Sulphoxine immobilized onto chitosan microspheres by spray drying: application for metal ions preconcentration by flow injection analysis, Talanta 63 (2004) 397-403.

[8] H.F. Maltez, L.F.C. Melo, S.C.N. Queiroz, I.C.S.F. Jardim, A.J. Curtuis, E. Carasek, A comparative study of homemade $\mathrm{C} 18$ and commercial C18 sorbents for preconcentration of lead by mini-column solid-phase extraction, Microchim. Acta 144 (2004) 17-21.

[9] E.L. Silva, A.O. Martins, A. Valentini, V.T. Fávere, E. Carasek, Application of silica gel organofunctionalized with 3-(1-imidazolyl)propyl in an on-line preconcentration system for the determination of copper by FAAS, Talanta 64 (2004) 181-189.

[10] S.A.C. Ferreira, A.C.S. Costa, M.G.A. Korn, Preliminary evaluation of the cadmium concentration in seawater of the Salvador City, Brazil, Microchem. J. 78 (2004) 77-83.

[11] M. Soylak, L. Elci, M. Dogan, Flame atomic absorption spectrometry determination of cadmium, cobalt, copper, lead and nickel in chemical grade potassium salts after an enrichment and separation procedure, J. Trace Microprobe Tech. 17 (1999) 149-156.

[12] M. Soylak, I. Narin, On-line preconcentration system for cadmium determination in environmental samples by flame atomic absorption spectrometry, Chem. Anal. (Warsaw) 50 (2005) 705-715.

[13] E. Melek, M. Tuzen, M. Soylak, Flame atomic absorption spectrometry determination of cadmium(II) and lead(II) after their solid-phase extraction as dibenzyldithiocarbamate chelates on Dowex Optipore V-493, Anal. Chim. Acta 578 (2006) 213-219.
[14] D.M. Wu, A.X. Wang, L.P. Guo, Synthesis and application of amberlite XAD-2 functionalized with dithizone for field preconcentration and separation of trace cadmium in seawater, Anal. Sci. 22 (2006) 1245-1248.

[15] F. Shemirani, B.T.S. Akhavi, Preconcentration and determination of trace cadmium using 1-(2-pyridylazo)-2-naphthol (PAN) immobilized on surfactant-coated alumina, Anal. Lett. 34 (2001) 2179-2188.

[16] E.M. Soliman, M.B. Saleh, S.A. Almed, Alumina modified by dimethyl sulfoxide as a new selective solid-phase extractor for separation and preconcentration of inorganic mercury(II), Talanta 69 (2005) 55-60.

[17] W. Hu, B. Hu, Z. Jiang, On-line preconcentration and separation of Co, $\mathrm{Ni}$ and $\mathrm{Cd}$ via capillary microextraction on ordered mesoporous alumina coating and determination by inductively plasma mass spectrometry (ICPMS), Anal. Chim. Acta 572 (2006) 55-62.

[18] J. Yin, Z. Jiang, G. Chang, B. Hu, Simultaneous on-line preconcentration and determination of trace metals in environmental samples by flow injection combined with inductively coupled plasma mass spectrometry using a nanometer-sized alumina packed microcolumn, Anal. Chim. Acta 540 (2005) 333-339.

[19] S.T. Fujiwara, Y. Gushikem, R.V.S. Alfaya, Adsorption of $\mathrm{FeCl}_{3}, \mathrm{CuCl}_{2}$ and $\mathrm{ZnCl}_{2}$ on silsesquioxane 3-n-propylpyridiniumchloride polymer film adsorbed on $\mathrm{Al}_{2} \mathrm{O}_{3}$-coated silica gel, Colloids Surf., A: Physicochem. Eng. Aspects 178 (2001) 135-141.

[20] S. Dadfarnia, M.H. Jafarzadeh, Online trace enrichment and determination of cobalt ion as an anionic complex by flow injection atomic absorption spectrometry, Microchem. J. 63 (1999) 226-234.

[21] D.H. Doehlert, Uniform shell designs, Appl. Stat. (1970) 231-239.

[22] M.A. Bezerra, A.L.B. Conceição, S.L.C. Ferreira, Doehlert matrix for optimisation of procedure for determination of nickel in saline oil-refinery effluents by use of flame atomic absorption spectrometry after preconcentration by cloud-point extraction, Anal. Bioanal. Chem. 378 (2004) 798-803.

[23] M. Zougagh, P.C. Rudner, A.G. Torres, J.M.C. Pavon, Application of Doehlert matrix and factorial designs in the optimization of experimental variables associated with the on-line preconcentration and determination of zinc by flow injection inductively coupled plasma atomic emission spectrometry, JAAS 15 (2000) 1589-1594.

[24] J.A.A. Amaro, S.L.C. Ferreira, Application of factorial design and Doehlert matrix in the optimization of instrumental parameters for direct determination of silicon in naphtha using graphite furnace atomic absorption spectrometry, JAAS 19 (2004) 1-5.

[25] S.L.C. Ferreira, A.S. Queiroz, M.S. Fernandes, H.C. Santos, Application of factorial designs and Doehlert matrix in optimization of experimental variables associated with the preconcentration and determination of vanadium and copper in seawater by inductively coupled plasma optical emission spectrometry, Spectrochim. Acta B 57 (2002) 19391950. 